\title{
Effect of Ca and Al Additions on the Magnetic Properties of Nanocrytalline Fe-Si-B-Nb-Cu Alloy Powder Cores
}

\author{
Sun Gyu Moon, Ji Seung Kim, Keun Yong Sohn, and Won-Wook Park* \\ Department of Nano System Engineering, Inje University, 607 Obang-dong, Gimhae, Gyungnam 50834, Republic of Korea
}

(Received 10 November 2015, Received in final form 22 March 2016, Accepted 8 April 2016)

\begin{abstract}
The Fe-Si-B-Nb-Cu alloys containing $\mathrm{Ca}$ and $\mathrm{Al}$ were rapidly solidified to thin ribbons by melt-spinning. The ribbons were ball-milled to make powders, and then mixed with $1 \mathrm{wt} . \%$ water glass and $1.5 \mathrm{wt} . \%$ lubricant. The mixed powders were burn-off, and then compacted to form toroidal-shaped cores, which were heat treated to crystallize the nano-grain structure and to remove residual stress of material. The characteristics of the powder cores were analyzed using a differential scanning calorimetry (DSC) and a B-H meter. The microstructures were observed using transmission electron microscope (TEM). The optimized soft magnetic properties $\left(\mu_{\mathrm{i}}\right.$ and $\left.\mathrm{P}_{\mathrm{cv}}\right)$ of the powder cores were obtained from the $\mathrm{Ca}$ and $\mathrm{Al}$ containing alloys after annealing at $530{ }^{\circ} \mathrm{C}$ for $1 \mathrm{~h}$. The core loss of $\mathrm{Fe}-\mathrm{Si}-\mathrm{B}-\mathrm{Nb}$-Cu-based powder cores was reduced by the addition of $\mathrm{Ca}$ element, and the initial permeability increased due to the addition of $\mathrm{Al}$ element.
\end{abstract}

Keywords : nanocrystalline, crystallization, grain size, permeability, coercivity, core loss

\section{Introduction}

The advanced amorphous and nanostructured soft magnetic materials have been developed by a plenty of research groups [1-5]. A large number of studies have been carried out in terms of their fundamentals and applications continuously $[6,7]$, resulting in the commercialization of the nanocrystalline soft magnetic materials with the nominal composition $\mathrm{Fe}_{73.5} \mathrm{Si}_{13.5} \mathrm{~B}_{9} \mathrm{Nb}_{3} \mathrm{Cu}_{1}$ known as Finemet alloy [8-10]. The alloy showed the excellent soft magnetic properties such as high permeability $\left(\mu_{\mathrm{e}}\right)$, high saturation magnetization $\left(\mathrm{M}_{\mathrm{s}}\right)$, high Curie temperature $\left(T_{c}\right)$ and very low coercivity $\left(H_{c}\right)$ [11-15], of which microstructure consisted of nanocrystalline $\alpha-\mathrm{Fe}(\mathrm{Si}) \mathrm{em}-$ bedded in an amorphous matrix [16-22]. The combination of small grain size and soft magnetic properties is surprising and fascinating from the classical point of view in magnetic engineering [23].

Recently, the soft magnetic composites (SMCs), composed of magnetic powders and insulation substance, are getting extended use in motors, actuators, power transformers, relays, inductors power circuits, communication devices, and microelectronics $[24,25]$. They offer a wide

CThe Korean Magnetics Society. All rights reserved.

*Corresponding author: Tel: +82-55-320-3872

Fax: +82-55-334-0748, e-mail: wwpark@inje.ac.kr range of manufacturing, environmental and technical benefits over the conventional magnetic sheet or laminates [26-29]. The ball milling techniques are generally suitable for preparation of SMCs because these techniques can crush the amorphous alloys to powder form, which is well suited for compression and densification of various shaped parts.

Therefore, it is interesting to prepare the nanocrystalline powder cores, and to analyze their microstructure and magnetic properties. Further, according to the reported and previous studies [30-32], the addition of $\mathrm{Al}$ caused the anisotropy and magnetostriction to become nearly zero so that the magnetic properties were improved, and the addition of $\mathrm{Ca}$ increased the electrical resistivity and reduced the core loss of the toroidal-shaped ribbon cores. In this study, the effect of $\mathrm{Ca}$ and $\mathrm{Al}$ additions on the magnetic properties of nanocrytalline $\mathrm{Fe}-\mathrm{Si}-\mathrm{B}-\mathrm{Nb}-\mathrm{Cu}$ alloy powder cores has been investigated at a high frequency range, and their microstructural changes were also observed after heat treatment at various temperatures.

\section{Experimental Procedure}

The $\mathrm{Fe}_{73.5} \mathrm{Si}_{13.5} \mathrm{~B}_{9} \mathrm{Nb}_{3} \mathrm{Cu}_{1}$ (at.\%) containing calcium and aluminum ingots were melt-spun at the cooling rate of about one million ${ }^{\circ} \mathrm{C} / \mathrm{sec}$. The obtained ribbons were basically in amorphous state, of which thickness of the 
amorphous ribbons were $20-22 \mu \mathrm{m}$. To obtain the powders, the ribbons were annealed at $425{ }^{\circ} \mathrm{C}$ for $60 \mathrm{~min}$ in an argon gas atmosphere before pulverization. The preannealed ribbons were ball-milled at $116 \mathrm{rpm}$ for $48 \mathrm{~h}$, resulting in the powder of less than $100 \mu \mathrm{m}$ in diameter. The particle size of calcium-containing alloys were smaller than that of Fe-based alloy without $\mathrm{Ca}$, which was caused by the brittleness of $\mathrm{Ca}$ containing alloys. Thus, the pulverized powders were screened with sieving, the powders of -200 mesh in size were used for this study. Subsequently, those screened powders were mixed with $1.0 \mathrm{wt} . \%$ water glass diluted by distilled water at the ratio of $1: 2$ (binder : DI water). For the compaction of the powder mixture with $1.5 \mathrm{wt} \%$ of lubricant, the compaction pressure of $30-35 \mathrm{ton} / \mathrm{cm}^{3}$ was applied to make the toroidal powder cores with $18 \mathrm{~mm}$ in outer diameter, $10 \mathrm{~mm}$ in inner diameter, and $6.35 \mathrm{~mm}$ in height. The powder compacts were then heat treated at $510-550{ }^{\circ} \mathrm{C}$ under a nitrogen atmosphere for $1 \mathrm{~h}$ to optimize the grain structure after crystallization, respectively. The magnetic properties such as the permeability and core loss of the soft magnetic composite core were investigated using a B-H analyzer and a flux meter at the high frequency range of $100 \mathrm{kHz}$ at 0.1 Tesla. The microstructure of SMC cores after thinning process was analyzed using a transmission electron microscope (TEM).

\section{Results and Discussion}

The chemical compositions of melt-spun Fe-based alloy ribbons (Fe-Si-B-Nb-Cu, Fe-Si-B-Nb-Cu-Ca, and Fe-Si$\mathrm{B}-\mathrm{Nb}-\mathrm{Cu}-\mathrm{Ca}-\mathrm{Al}$ base) were determined using a inductively coupled plasma (ICP) analyzer as shown in Table 1. The structure of ribbons was in amorphous state to be crystallized for the nano-grain structure: The annealing temperature was decided from the differential scanning calorimetry (DSC) results of the alloy ribbons. Figure 1 shows the DSC curves of the ribbons, indicating the relationship between the glass transition temperature $\left(T_{g}\right)$, and the first and second crystallization temperature $\left(\mathrm{T}_{\mathrm{x} 1}\right.$ for $\alpha-\mathrm{Fe}(\mathrm{Si})$ and $\mathrm{T}_{\mathrm{x} 2}$ for $\mathrm{Fe}$-boride) $[32,33]$. The $\mathrm{Ca}$ and $\mathrm{Al}$ containing alloy showed the relatively large temperature gap $(\Delta \mathrm{T})$ between $\mathrm{T}_{\mathrm{x} 1}$ and $\mathrm{T}_{\mathrm{x} 2}$, compared to the other

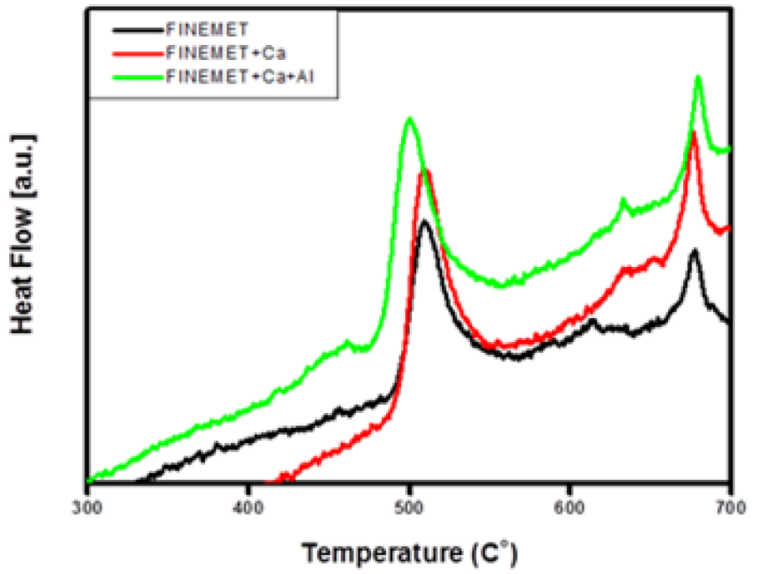

Fig. 1. (Color online) DSC curves of Fe-based nanocrystalline soft magnetic alloys obtained at a heating rate of $15 \mathrm{~K} / \mathrm{min}$.

alloys. Based on the results, it can be concluded that $\mathrm{Ca}$ and $\mathrm{Al}$ additions generally improve the thermal stability of the nanocrystalline structure of the $\alpha-\mathrm{Fe}(\mathrm{Si})$ phase [3438].

In order to obtain the fine particles, the melt-spun ribbons were ball-milled on the same condition. However, the average powder sizes of the alloy ribbons were different each other, which was attributed to the difference in intrinsic brittleness according to the each alloy composition. The particle sizes of calcium-containing alloys were smaller than that of Fe-based alloy without $\mathrm{Ca}$, implying that the $\mathrm{Ca}$ addition increased the brittleness of the rapidly solidified amorphous alloy ribbons. Thus, it was analyzed that the alloy ribbon containing $\mathrm{Ca}$ was easily purverized, which is considered very helpful for the fabrication process of amorphous powder making. As to the binder for insulation between the particles, the diluted water glass was desirable to obtain a uniform dispersion and to increase the strength of the powder cores. Thus, the powders mixed with the diluted binder were dried at room temperature in air for $2 \mathrm{~h}$ to vaporize the water contained in the binder. Futher, the Fe-based powders mixed with the binder were pressed to form a toroidalshaped core by a cold-compaction process at 30-35 ton/ $\mathrm{cm}^{2}$.

According to the previous research on the ribbon cores

Table 1. ICP results of the Fe-based alloy ribbons.

(Alloy systems : (a) Fe-Si-B-Nb-Cu, (b) Fe-Si-B-Nb-Cu-Ca, (c) Fe-Si-B-Nb-Cu-Ca-Al)

\begin{tabular}{cccccccccc}
\hline \hline & Element & $\mathrm{Fe}$ & $\mathrm{Si}$ & $\mathrm{B}$ & $\mathrm{Nb}$ & $\mathrm{Cu}$ & $\mathrm{Ca}$ & Al & Totals \\
\hline $\mathrm{a}$ & weight $\%$ & 82.94 & 9.72 & 1.24 & 4.86 & 1.24 & - & - & $\sim 100$ \\
$\mathrm{~b}$ & weight $\%$ & 82.42 & 9.84 & 1.17 & 4.95 & 1.57 & $\mathbf{0 . 0 5}$ & - & $\sim 100$ \\
$\mathrm{c}$ & Weight\% & 82.33 & 9.72 & 1.20 & 4.80 & 1.35 & $\mathbf{0 . 0 5}$ & $\mathbf{0 . 5 9}$ & $\sim 100$ \\
\hline
\end{tabular}




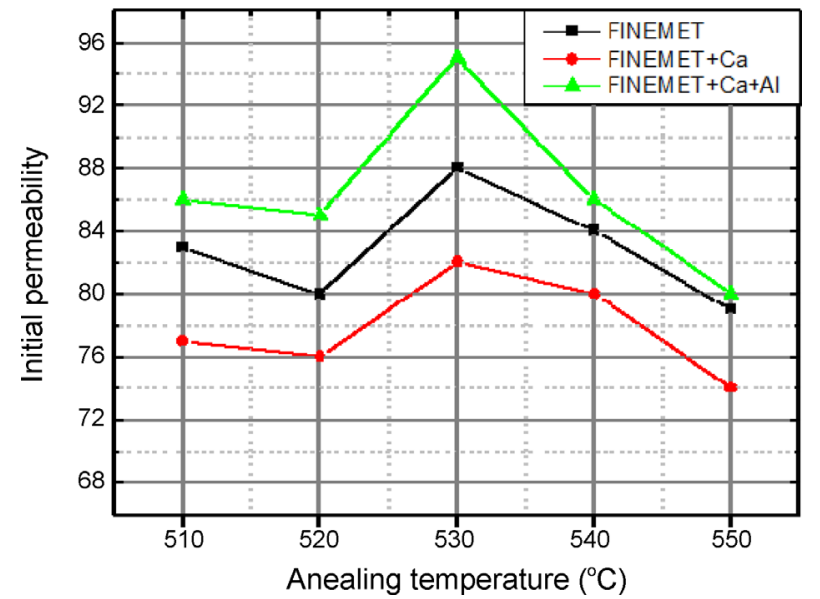

Fig. 2. (Color online) The initial permeability changes of the powder cores after annealing at the various temperatures (measured at $100 \mathrm{kHz}, 0.1 \mathrm{~T}$ ).

of the nanostructured soft magnetic alloys [31], the Febased alloy containing $\mathrm{Ca}$ and $\mathrm{Al}$ showed the highest applied field permeability after annealing at $550{ }^{\circ} \mathrm{C}$ for 1 $\mathrm{h}$ among the $\mathrm{Fe}-\mathrm{Si}-\mathrm{B}-\mathrm{Nb}-\mathrm{Cu}$ base alloys. The core loss of the $\mathrm{Fe}-\mathrm{Si}-\mathrm{B}-\mathrm{Nb}-\mathrm{Cu}$ ribbon core containing $\mathrm{Ca}$ and $\mathrm{Al}$ was lower than that of the Fe-Si-B-Nb-Cu alloy core.

Similarly, the additions of $\mathrm{Ca}$ and $\mathrm{Al}$ affected the magnetic properties of the $\mathrm{Fe}-\mathrm{Si}-\mathrm{B}-\mathrm{Nb}-\mathrm{Cu}$ base powder cores. The initial permeability $\left(\mu_{\mathrm{i}}\right)$ of the powder cores with annealing temperature $\left(\mathrm{T}_{\mathrm{a}}\right)$ was determined at 100 $\mathrm{kHz}$ under an applied magnetic field of $0.1 \mathrm{~T}$, as seen in Fig. 2. The initial permeability of the $\mathrm{Fe}-\mathrm{Si}-\mathrm{B}-\mathrm{Nb}-\mathrm{Cu}$ alloy containing $\mathrm{Ca}$ and $\mathrm{Al}$ showed the high value $\left(\mu_{\mathrm{i}}=\right.$ 95) when annealed at $530{ }^{\circ} \mathrm{C}$ for $1 \mathrm{~h}$, compared to the FeSi-B-Nb-Cu alloy $(\mu \mathrm{i}=88)$ and the Ca-containing alloys $\left(\mu_{\mathrm{i}}=82\right)$. The initial permeability could be increased with the addition of $\mathrm{Al}$ to the Fe-based alloy powder, of which results were almost the same as the ribbon cores. The annealing temperature $\left(T_{a}\right)$ dependency of the core loss $\left(\mathrm{P}_{\mathrm{cv}}\right)$ is shown in Fig. 3. The core loss of the Fe-based powder cores was measured at $100 \mathrm{kHz}$ under an applied magnetic field of $0.1 \mathrm{~T}$. The lowest value $\left(\mathrm{P}_{\mathrm{cv}}=1100\right.$ $\mathrm{mW} / \mathrm{cm}^{3}$ ) was obtained from the Ca containing powder core when annealed at $530{ }^{\circ} \mathrm{C}$ for $1 \mathrm{~h}$. The core loss of the $\mathrm{Fe}-\mathrm{Si}-\mathrm{B}-\mathrm{Nb}-\mathrm{Cu}$ alloy containing $\mathrm{Ca}$ and $\mathrm{Al}$ showed a little higher value $\left(\mathrm{P}_{\mathrm{cv}}=1171 \mathrm{~mW} / \mathrm{cm}^{3}\right)$ than that of $\mathrm{Ca}-$ containing alloy powder core. However, there was no big difference in core loss value. The $\mathrm{Ca}$ content was effective to minimize the eddy current loss and to reduce core loss with the increase of electrical resistivity. The core loss remarkably decreased due to the insulation of the powders, when the binder was uniformly coated on the powder surface. The perfect insulation between particles

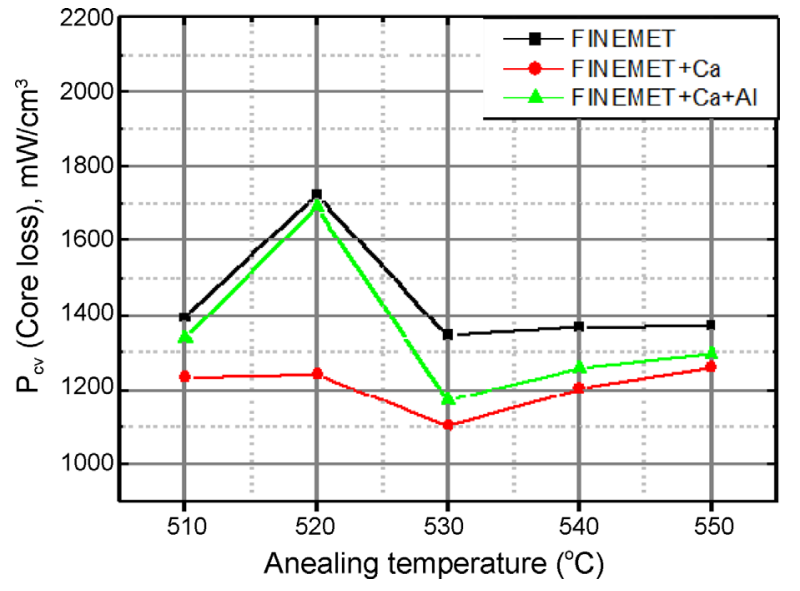

Fig. 3. (Color online) The core loss variations of the powder cores with annealing temperature (measured at $100 \mathrm{kHz}$, $0.1 \mathrm{~T})$.

are generally required to minimize eddy current in high frequency applications. The optimized soft magnetic properties $\left(\mu_{\mathrm{i}}\right.$ and $\left.\mathrm{P}_{\mathrm{cv}}\right)$ of the powder cores were obtained from the $\mathrm{Ca}$ and $\mathrm{Al}$ containing alloys after annealing at $530{ }^{\circ} \mathrm{C}$ for $1 \mathrm{~h}$. The optimized magnetic properties of each core alloy, annealed at $530{ }^{\circ} \mathrm{C}$ for $1 \mathrm{~h}$, were summarized in Table 2. Based on the results, the core loss of Fe-Si-B-Nb-Cu-based powder cores was reduced mainly by the addition of $\mathrm{Ca}$ element, and the initial permeability increased effectively due to the addition of $\mathrm{Al}$ element.

To analyze the nanograin structures of SMC cores, the transmission electron microscopy (TEM) were investigated in detail. Among the alloy powder cores, the Fe-Si$\mathrm{B}-\mathrm{Nb}-\mathrm{Cu}-\mathrm{Ca}-\mathrm{Al}$ alloy showed the smallest nanostructure after annealing at $530{ }^{\circ} \mathrm{C}$ for $1 \mathrm{~h}$ (as shown in Fig. 4), implying that these additional elements could stabilize the nano-structure of the Fe-based alloy powders, and the stored energy generated during the powder process didn't pronouncedly increase the driving force for grain growth.

This result was corresponding to the previous work [31] on the alloy ribbons. The addition of $\mathrm{Ca}$ and $\mathrm{Al}$ elements inhibited the grain growth of the nano-structured alloy

Table 2. The maximum value of initial permeability and the minimum value of core loss with each frequency ( $\mathrm{f}=100 \mathrm{kHz}$ ) after the optimized annealing at $530^{\circ} \mathrm{C}$ for $1 \mathrm{~h}$.

\begin{tabular}{lccc}
\hline \hline \multirow{2}{*}{ Alloy } & Permeability & & Core loss $\left(\mathrm{mW} / \mathrm{cm}^{3}\right)$ \\
\cline { 2 - 2 } & $100 \mathrm{kHz}, 0.1 \mathrm{~T}$ & & $100 \mathrm{kHz}, 0.1 \mathrm{~T}$ \\
\hline Fe-Si-B-Nb-Cu & 88 & 1345 \\
Fe-Si-B-Nb-Cu-Ca & 82 & 1100 \\
Fe-Si-B-Nb-Cu-Ca-Al & 95 & 1171 \\
\hline
\end{tabular}



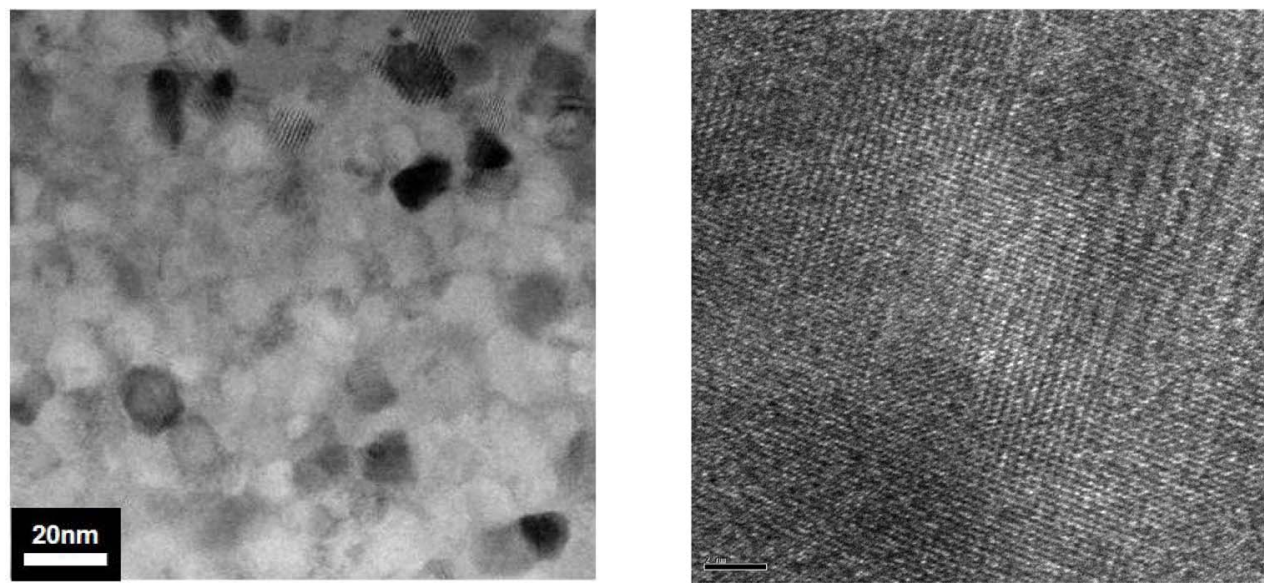

Fig. 4. TEM images of $\mathrm{Fe}-\mathrm{Si}-\mathrm{B}-\mathrm{Nb}-\mathrm{Cu}-\mathrm{Ca}-\mathrm{Al}$ nanocrystalline core particles after crystallization process (annealing at $530{ }^{\circ} \mathrm{C}$ for $1 \mathrm{~h}$ ), showing the photo-image of $\times 500,000$ (left) and $\times 5,000,000$ (right) in magnification.

powder as well as the alloy ribbons, resulting in the stabilization of the nanocrystalline structure. According to G. Herzer [39], the TEM results provided direct evidence for the improvement in the soft magnetic properties. The $\mathrm{Al}$ element was analyzed to be solid-solutionized in the $\alpha$ $\mathrm{Fe}$ phase, which led to the reduction of the crystal anisotropy of the soft magnetic composites. On the contrary, it was not easy to identify the Ca clusters or its compounds in the matrix and boundaries, implying that more $\mathrm{Ca}$ amount should be added to understand its effect on the stabilization of the nanostructure clearly. Based on the results, the additions of $\mathrm{Ca}$ and $\mathrm{Al}$ decreased the growth rate of the nano-grain, which stabilized the nanostructure of Fe-Si-B-Nb-Cu base alloys and improved the magnetic properties such as the initial permeability and core loss of the powder cores. In this respect, it can be concluded that the addition of $\mathrm{Ca}$ and $\mathrm{Al}$ to the Fe-Si-B$\mathrm{Nb}-\mathrm{Cu}$ base alloys was effective for the improvement of the soft magnetic properties to expand the application areas of soft magnetic powder cores.

\section{Conclusions}

Rapidly solidified $\mathrm{Fe}-\mathrm{Si}-\mathrm{B}-\mathrm{Nb}-\mathrm{Cu}$ alloy powders containing $\mathrm{Ca}$ and $\mathrm{Al}$ were compacted to toroidal soft magnetic composite (SMC) cores, and the magnetic properties were analyzed in detail. Based on the experimental results, the following conclusions were drawn:

1. The optimized soft magnetic properties $\left(\mu_{\mathrm{i}}\right.$ and $\left.\mathrm{P}_{\mathrm{cv}}\right)$ of the powder cores were obtained from the $\mathrm{Ca}$ and $\mathrm{Al}$ containing alloys after annealing at $530{ }^{\circ} \mathrm{C}$ for $1 \mathrm{~h}$. The core loss of $\mathrm{Fe}-\mathrm{Si}-\mathrm{B}-\mathrm{Nb}-\mathrm{Cu}-\mathrm{based}$ powder cores was reduced mainly by the addition of $\mathrm{Ca}$ element, and the initial permeability increased effectively due to the addition of $\mathrm{Al}$ element. The $\mathrm{Ca}$ cluster or its compound was not observed in the crystallized grain structure.

2. The grain size of Fe-Si-B-Nb-Cu alloy powder cores containing $\mathrm{Ca}$ and $\mathrm{Al}$ was very fine compared to the other alloy powders, implying that these additional elements could inhibit the grain growth of the Fe-based alloy powders, and the stored energy generated during the powder process didn't pronouncedly increase the driving force for grain growth.

3. The Fe-based alloy ribbons containing $\mathrm{Ca}$ and $\mathrm{Al}$ showed the desireable characteristics for powder making in that the alloy ribbon was easily purverized because of $\mathrm{Ca}$ addition, which is considered very helpful in terms of the energy saving for the powder fabrication.

\section{Acknowledgement}

This research was supported by Basic Science Research Program through the National Research Foundation of Korea (NRF) funded by the Ministry of Education, Science and Technology (2013 R1A1A01010423).

\section{References}

[1] P. Duwez, Asm Trans Quart. 60, 605 (1967).

[2] M. Mitera, M. Naka, T. Masumoto, N. Kazama, and K. Watanabe, Phys. Status Solidi A 49, K163 (1978).

[3] F. Luborsky, J. Becker, J. L. Walter, and H. H. Liebermann, IEEE Trans. Magn. 15, 1146 (1979).

[4] A. Inoue, T. Masumoto, M. Kikuchi, and T. Minemura, Sci. Rep. Res. Inst. Tohoku Univ., A 27, 127 (1979).

[5] M. Mitera, T. Masumoto, and N. Kazama, J. Appl. Phys. 50, 7609 (1979).

[6] M. E. McHenry, M. A. Willard, and D. E. Laughlin, Prog. Mater Sci. 44, 291 (1999).

[7] R. Hasegawa, J. Non-Cryst. Solids 287, 405 (2001).

[8] Y. Yoshizawa, S. Oguma, and K. Yamauchi, J. Appl. 
Phys. 64, 6044 (1988).

[9] Y. Yoshizawa and K. Yamauchi, Mater. Trans., JIM 31, 307 (1990).

[10] Y. Yoshizawa and K. Yamauchi, IEEE Trans. Magn. 25, 3324 (1989).

[11] K. Suzuki, N. Kataoka, A. Inoue, A. Makino, and T. Masumoto, Mater. Trans., JIM 31, 743 (1990).

[12] Y. Fujii, H. Fujita, A. Seki, and T. Tomida, J. Appl. Phys. 70, 6241 (1991).

[13] K. Suzuki, A. Makino, A. Inoue, and T. Masumoto, Sci. Rep. Res. Inst. Tohoku Univ., A 39, 133 (1994).

[14] A. Makino, A. Inoue, and T. Masumoto, Mater. Trans., JIM 36, 924 (1995).

[15] A. Makino, T. Hatanai, Y. Naitoh, T. Bitoh, A. Inoue, and T. Masumoto, IEEE Trans. Magn. 33, 3793 (1997).

[16] G. Herzer, Acta Mater. 61, 718 (2013).

[17] G. Herzer, Mater. Sci. Eng., A 133, 1 (1991).

[18] S. Flohrer, R. Schäfer, and G. Herzer, J. Non-Cryst. Solids 354, 5097 (2008).

[19] G. Herzer, S. Flohrer, and C. Polak, IEEE Trans. Magn. 46, 341 (2010).

[20] K. Hono, A. Inoue, and T. Sakurai, Appl. Phys. Lett. 58, 2180 (1991).

[21] G. Herzer, Handbook of Magnetic Materials 10, 415 (1997).

[22] K. Hono, D. Ping, M. Ohnuma, and H. Onodera, Acta Mater. 47, 997 (1999).

[23] G. Herzer, V. Budinsky, and C. Polak, Phys. Status Solidi B 248, 2382 (2011).

[24] S. E. Lyshevski and K. S. Martirosyan: Proc. 11th IEEE
Int. Conf. Nanotechnol. (IEEE'11) 1252 (2011).

[25] J. Park and M. Allen, J. Micromech. Microeng. 8, 307 (1998).

[26] A. Kordecki and B. Weglinski, Powder Metall. 33, 151 (1990).

[27] A. Jack, Conf. Electrical Machines (ICEM'98), 1441 (1998).

[28] T. Lipo, S. Madani, R. White, and W. Ouyang, 11th Int. Power Electronics and Motion Control Conf. (EPEPEMC 2004) (2004).

[29] M. Persson, P. Jansson, A. Jack, and B. Mecrow, Hoganeas Iron Powder Information (PM95-4), 8 (1995).

[30] G. Herzer, J. Magn. Magn. Mater. 157, 133 (1996).

[31] S. K. Nam, S. G. Moon, K. Y. Sohn, and W. W. Park, J. Magn. 19, 327 (2014).

[32] M. R. Kim, S. I. Kim, K. S. Kim, K. Y. Sohn, and W. W. Park, Met. Mater. Int. 18, 185 (2012).

[33] Y. Yoshizawa and K. Yamauchi, Mater. Sci. Eng., A 133, 176 (1991).

[34] B. Tate, B. Parmar, I. Todd, H. Davies, M. Gibbs, and R. Major, J. Appl. Phys. 83, 6335 (1998).

[35] S. Lim, W. Pi, T. Noh, H. Kim, and I. Kang, J. Appl. Phys. 73, 6591 (1993).

[36] A. Zorkovská, J. Kováč, P. Sovák, P. Petrovič, and M. Konč, J. Magn. Magn. Mater. 215, 492 (2000).

[37] P. Warren, I. Todd, H. Davies, A. Cerezo, M. Gibbs, D. Kendall, and R. Major, Scr. Mater. 41, 1223 (1999).

[38] A. Inoue, A. Kitamura, and T. Masumoto, J. Mater. Sci. 16, 1895 (1981)

[39] G. Herzer, IEEE Trans. Magn. 25, 3327 (1989). 